\title{
Nickel Oxide Nanocrystalline Fabricated Under Gamma Irradiation and Its Photocatalytic Investigation for Textile Azo Dye Degradation
}

\author{
Ekoko Bakambo Gracien ${ }^{1, ~ *, ~ M u s w e m a ~ L u n g u y a ~ J e ́ r e ́ m i e ~}{ }^{1}$, Lobo Kanza-Kanza Joseph ${ }^{1}$, \\ Mvele Muamba Omer ${ }^{1}$, Nzazi Kambamba Nicole ${ }^{2}$, Nduku Mafwa Fabrice ${ }^{3}$, \\ Musengele Bilasi Denis ${ }^{3}$, Ndonganzadi Tresor ${ }^{3}$, Mukiatom Perbon ${ }^{4}$, Mata Niasa Gérard ${ }^{1}$ \\ ${ }^{1}$ Department of Chemistry, University of Kinshasa, Kinshasa, Democratic Republic of the Congo \\ ${ }^{2}$ Department of Biological Chemistry, High Educational Institute of Kitoy, Masimanimba, Democratic Republic of the Congo \\ ${ }^{3}$ Department of Physical Chemistry, High Educational Institute of Kikwit, Kikwit, Democratic Republic of the Congo \\ ${ }^{4}$ Department of Construction, Institute of Construction and Public Works of Kikwit, Kikwit, Democratic Republic of the Congo
}

Email address:

profekokob@yahoo.fr (E. B. Gracien)

${ }^{*}$ Corresponding author

\section{To cite this article:}

Ekoko Bakambo Gracien, Muswema Lunguya Jérémie, Lobo Kanza-Kanza Joseph, Mvele Muamba Omer, Nzazi Kambamba Nicole, Nduku Mafwa Fabrice, Musengele Bilasi Denis, Ndonganzadi Tresor, Mukiatom Perdon, Mata Niasa Gérard. Nickel Oxide Nanocrystalline Fabricated Under Gamma Irradiation and Its Photocatalytic Investigation for Textile Azo Dye Degradation. Advances in Materials. Vol. 8, No. 3, 2019, pp. 112-119. doi: 10.11648/j.am.20190803.13

Received: July 4, 2019; Accepted: July 25, 2019; Published: August 13, 2019

\begin{abstract}
Gamma irradiation technique has been applied to produce non-stoichiometric nickel oxide nanoparticles (of approximately $23 \mathrm{~nm}$ ) from gels prepared at $\mathrm{pH}$ about 8.2. Characterization techniques so far discussed in this investigation revealed that the sol product prepared before irradiation corresponded to $\mathrm{Ni}(\mathrm{OH})_{2}$, which was transformed under gamma irradiation to $\mathrm{NiO}$. The present investigation has proven the efficiency of gamma rays in inducing changes in structure and morphology of the sols prepared before irradiation. The synthesised $\mathrm{NiO}$ nanoparticle was found to be an efficient photocatalyst for degradation of acid red G under UV light irradiation. And, finally the radiolytic mechanism production of $\mathrm{NiO}$ nanoparticles in aerated solutions is suggested according to the experimental result.
\end{abstract}

Keywords: Nickel Oxide, $\gamma$-Irradiation Method, Acid Red G, Photocatalysis

\section{Introduction}

Nanostructured materials have been extensively explored for the fundamental scientific and technological interests in accessing new classes of functional materials with unprecedented properties and applications.

$\mathrm{NiO}$, a well characterized oxide of nickel exists in two forms in nature: (i) rhombohedral, black in colour and is antiferromagnetic; (ii) cubic form, green in colour and paramagnetic in [1]. Among magnetic nanoparticles it is difficult to synthesize $\mathrm{NiO}$ nanoparticles as they easily get oxidize. Like many other binary metal oxides, $\mathrm{NiO}$ is often non-stoichiometric, meaning that the $\mathrm{Ni}$ : $\mathrm{O}$ ratio deviates from 1:1. In nickel oxide this non-stoichiometry is accompanied by a colour change, with the stoichiometrically correct $\mathrm{NiO}$ being green, and the non-stoichiometric $\mathrm{NiO}$ being black. Green $\mathrm{NiO}$ adopts the $\mathrm{NaCl}$ structure, with octahedral $\mathrm{Ni}$ (II) and $\mathrm{O}_{2}^{-}$sites. The conceptually simple structure is commonly known as the rock salt structure [1].

Among transition metal oxides, nickel oxide (NiO) bulk and nano size have received considerable attention, owing to their wide range of applications in different fields, such as catalysis, fuel cell electrodes and gas sensors electrochromic films, battery cathodes, magnetic materials, and photovoltaic devices. Furthermore, $\mathrm{NiO}$ is being studied for applications in smart windows and electrochemical supercapacitors [2$11]$.

Because of the quantum size and surface effects, $\mathrm{NiO}$ 
nanoparticles exhibit catalytic, optical, electronic, and magnetic properties that are significantly different from those of bulk-sized NiO particles [12, 13].

$\mathrm{NiO}$ nanoparticles have been prepared by various methods like sol-gel, self-propagating low temperature combustion method, thermal decomposition, co-precipitation method, aqueous chemical growth techniques, surfactant-mediated synthesis, spray pyrolysis, and microwave irradiation. Hydrothermal / solvothermal synthesis have been proposed for producing metal oxide nanoparticles. However, these methods require long reaction times and use of organic solvents, which required additional processes for the complete synthesis. Some of the existing synthesis methods suffer from the difficulty in size-homogeneity and well dispersion of NiO nanoparticles [14, 15, 16-26].

The synthesis of metal oxides nanoparticles by gamma irradiation offers some advantages compared to those from conventional methods because it provides fully reduced and highly pure nanoparticles. The latter are free from byproducts or chemical reducing agents. This synthesis method is capable of controlling the size and structure of the particle. The size of nanoparticles is influenced by certain parameters such as the choice of solvents and stabilizer, the precursor to stabilizer ratio, $\mathrm{pH}$ during synthesis, and absorbed dose. This technique could hopefully, simplify the experimental process, which is an interesting strategy to produce new catalysts [2728].

In our previous works, $\gamma$-irradiation method has been applied to produce magnetic $\mathrm{Fe}_{3} \mathrm{O}_{4}$ nanorod particles, and spinel $\mathrm{Co}_{3} \mathrm{O}_{4}$ nanoparticles [29-31].

The present investigation reports on $\gamma$-irradiation as a facile technique to produce monodisperse non-stoichiometric $\mathrm{NiO}$ particles, which have been prepared by irradiating the starting aerated sol of $\mathrm{Ni}(\mathrm{OH})_{2}$, which was converted to the corresponded $\mathrm{NiO}$ at room temperature and ambient pressure. The synthezised material was characterized in order to find out about its structural and optical properties. Additionally, the phototocatalytic activity of the synthesized $\mathrm{NiO}$ was performed towards the degradation of acid red $\mathrm{G}$, which was chosen as a pollutant model.

\section{Experimental Details}

\subsection{Sample Preparation Procedure}

All the reagents used for producing nickel oxide nanoparticles were analytical grade with minimum assay 95\% and were purchased from Shanghai Chemical Reagent Co., Shanghai, China. They were used as received, without further purification. The following chemical reagents were used: heptahydrated nickel sulphate $\left[\mathrm{NiSO}_{4} .7 \mathrm{H}_{2} \mathrm{O}\right]$, as $\mathrm{Ni}^{2+}$ precursor, distilled water [ $\mathrm{H}_{2} \mathrm{O}$ ], isopropyl alcohol, $\left[\left(\mathrm{CH}_{3}\right)_{2} \mathrm{CHOH}\right]$, anhydrous sodium hydroxide, $[\mathrm{NaOH}]$, polyvinyl alcohol [PVA] and ammonium buffers $\left[\mathrm{NH}_{4} \mathrm{OH} /\left(\mathrm{NH}_{4}\right)_{2} \mathrm{SO}_{4}\right]$.

a. Preparation of $\mathrm{Ni}(\mathrm{OH})_{2}$ before $\gamma$-irradiation
Sols of $\mathrm{Ni}(\mathrm{OH})_{2}$ were prepared by firstly dissolving $9 \mathrm{~g}$ of analytically pure $\mathrm{NiSO}_{4} .7 \mathrm{H}_{2} \mathrm{O}$ in $400 \mathrm{~mL}$ of distilled water. Secondly, concentrated solution of anhydrous sodium hydroxide was added drop wise into the aqueous solution under constant stirring with a magnetic stirrer until the $\mathrm{pH}$ of the suspension increased to about 8.2. Ammonium buffers were ultimately chosen to avoid the irreversible precipitation of parasitic nickel salts. A green-coloured sol was obtained, which expect the formation of $\mathrm{Ni}(\mathrm{OH})_{2}$. The precipitate was separated from the main solution by repeated filtration and centrifugation and then washed by ethyl alcohol to eliminate soluble salts. The prepared precipitate was dried in vacuum oven at $60^{\circ} \mathrm{C}$ for 4 hours and analyzed by XRD. Its morphology was observed by TEM and SEM.

b. $\gamma$-irradiation fabrication of $\mathrm{NiO}$ nanoparticles

$10 \mathrm{~g}$ of the dried precipitate made of $\mathrm{Ni}(\mathrm{OH})_{2}$ were dissolved in $100 \mathrm{~mL}$ of distilled water. To improve the yield production of nanopowders oxides, isopropyl alcohol (3.0 mol L ${ }^{-1}$ ) was firstly poured into the solutions to act as scavenger for oxidative radicals $\mathrm{OH}$-produced during the radiolysis of water under gamma irradiation. To prevent the small particles from coming into close contact and undergoing further aggregation, an organic surfactant, polyvinyl alcohol, PVA $(1 \%, \mathrm{w} / \mathrm{w})$ was then added in the solution.

To measure the radiation dose as well as the dose rate delivered to the $\mathrm{Ni}(\mathrm{OH})_{2}$ solution, the dosimetry of gamma irradiator was measured by Fricke dosimetry and was found to be $0.25 \mathrm{kGy}$. The prepared sols were irradiated in the field of a ${ }^{60} \mathrm{Co} \gamma$-ray source of $1.2025 \times 1016 \mathrm{~Bq}(325000 \mathrm{Ci})$. The absorbed dose of irradiation was $30 \mathrm{kGy}$ with a dose rate of about $0.25 \mathrm{kGy} \mathrm{h}^{-1}$. After irradiation, black-coloured precipitates were obtained and were separated by washing with distilled water and absolute alcohol, in order to remove the by-products. They were finally dried in vacuum oven at $60^{\circ} \mathrm{C}$ for for 4 hours and then characterized. The change in the colour of the sols indicates the formation of nickel oxide nanoparticles.

\subsection{Characterization Techniques}

The structure and the phase identification of the prepared materials was carried out on X-ray powder diffraction (XRD) patterns, using a D/MAX-2550 Xray diffractometer with $\mathrm{Cu}$ $\mathrm{K} \alpha$ radiation $(\lambda=1.54056 \AA$ ) with a nickel filter (Rigaku Co., Japan). The crystalline sizes were calculated by using the Debye- Scherrer formula. The chemical bondings in $\mathrm{NiO}$ were recorded by Fourier transform infrared spectra (SHIMADZU Spectrophotometer) using $\mathrm{KBr}$ pellet technique in the range from $4000 \mathrm{~cm}^{-1}$ to $400 \mathrm{~cm}^{-1}$ (spectral resolution at $4 \mathrm{~cm}^{-1}$ and number of scans at 20). The surface morphology, size of particles and elemental compositions of $\mathrm{NiO}$ were carried out by field emission scanning electron microscopy (FE-SEM; JEOL JSM-6700F) well equipped with an energy dispersive X-ray (EDAX) spectrophotometer and operated at $20 \mathrm{kV}$. The chemical bonding on the composite surface was studied using X-ray photoelectron spectroscopy (XPS), which was performed with a Thermo 
VG Scientific ESCALAB 250 spectrometer with a monochromatized Al-K $\alpha$ X-ray source (1486.6 eV energy). Optical absorption measurements of the composites were performed using a UV-Vis spectrophotometer (Perkin Elmer) in $1 \mathrm{~cm}$ cuvettes at range between 200-600nm. A homogeneous suspension in distilled water, obtained through sonication (for 10 minutes) of well dispersed sample is used for UV-vis studies. The morphology and the particles size of $\mathrm{NiO}$ were determined by transmission electron microscopy (TEM; Hitachi H-800), and selected area electron diffraction (SAED). The TEM micrographs were taken with an accelerating voltage of $200 \mathrm{kV}$ with samples deposited on a carbon coated copper grid.

\section{Results and Discussion}

\subsection{Xrd Studies}

Figure 1 shows the X-ray diffraction pattern of the green powder formed before $\gamma$ - irradiation. XRD analysis showed that this substance is a typical $\alpha$-type nickel hydroxide powder with poor crystallinity. All of the diffraction peaks were broad and belonged to $\mathrm{Ni}(\mathrm{OH})_{2} \cdot 6 \mathrm{H}_{2} \mathrm{O}$ (JCPDS card No. 38-0715). The insert in figure 1, provides a typical SEM image of the $\mathrm{Ni}(\mathrm{OH})_{2}$ sample, illustrating irregular morphology with different micrometer-sized particles due to aggregation.

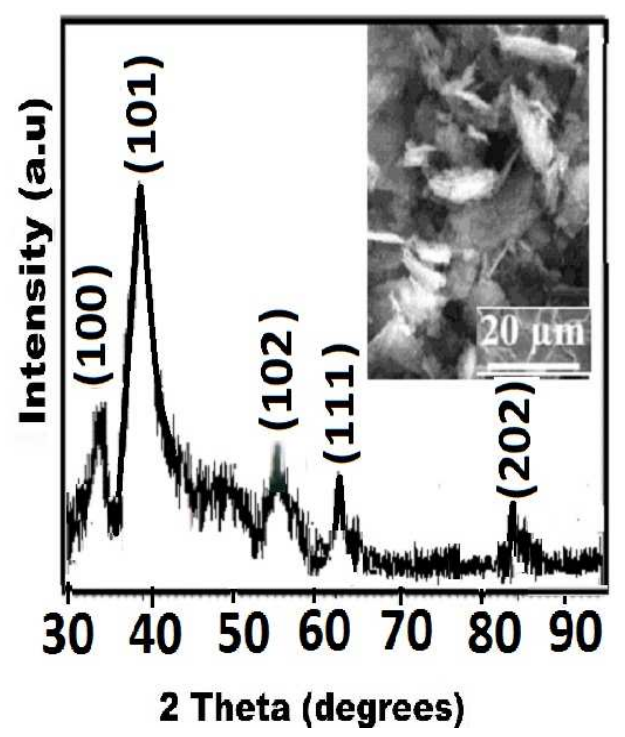

Figure 1. XRD pattern of of green-coloured $\mathrm{Ni}(\mathrm{OH})_{2}$ precursor, prepared at $p H=8.2$ before gamma irradiation. The various Bragg peaks are followed by corresponding Miller indices. Results were obtained using CuKa radiation $(\lambda=1.54178 A)$. The transmission electron micrograph, in insert, is of $\mathrm{Ni}$ $(\mathrm{OH})_{2}$ sol synthesized at room temperature $(\mathrm{pH}=8.2)$.

The XRD pattern (Figure 2) shows a series of intense peaks corresponding to reflections from the (111), (200), (220), (311) and (222) planes which occur angular positions of about $37.26,43.29,62.88,75.42$ and $79.41^{\circ}$ respectively as indexed to JCPDS card No. 22-1189. The presence of these peaks confirmed the formation of nickel oxide. No peaks due to $\mathrm{Ni}(\mathrm{OH})_{2}$ were found from XRD, indicating that
$\mathrm{Ni}(\mathrm{OH})_{2}$ was completely converted under $\gamma$-irradiation to $\mathrm{NiO}$, which is also confirmed by other characterization methods.

It is well known that, the green-coloured has commonly been reported for the stoichiometrically correct $\mathrm{NiO}$ semiconductor while the black-coloured being a nonstoichiometry $\mathrm{NiO}$. The fabricated product appeared in black color. The color deterioration was attributable to the nonstoichiometric character of the final $\mathrm{NiO}$ powder [32].

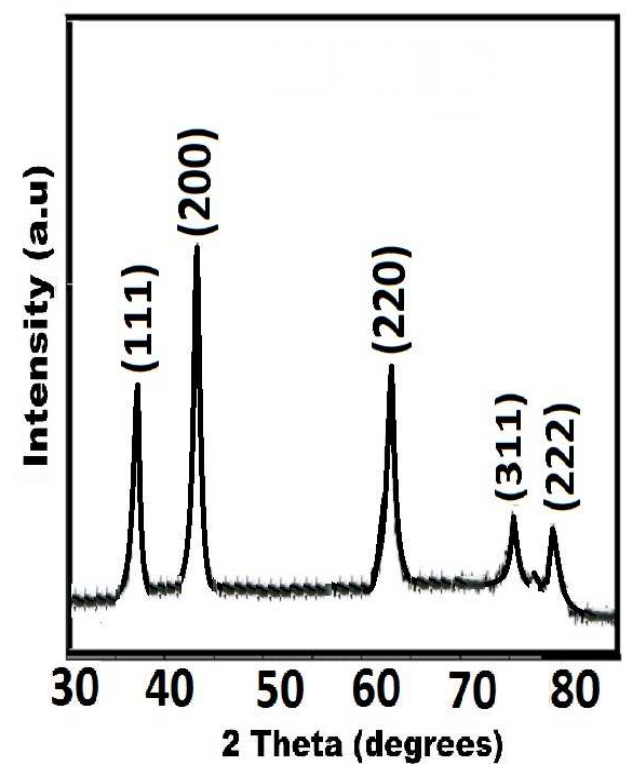

Figure 2. XRD pattern black-coloured $\mathrm{NiO}$ particles fabricated at $\mathrm{pH}=8.2$ under gamma irradiation. The various Bragg peaks are followed by corresponding Miller indices. Results were obtained using $\mathrm{CuK \alpha}$ radiation $(\lambda=1.54178 \AA)$.

Figure 1 shows poor crystallinity of $\mathrm{Ni}(\mathrm{OH})_{2}$ precursor while the semi-broad nature of the peaks at their base in Figure 2. indicates high crystallinity and suggests the nanoscaled nature of the $\mathrm{NiO}$ particles obtained under $\gamma$ irradiation. According to the Scherer equation, the mean crystallite size of the $\mathrm{NiO}$ calculated was found to be about $21 \mathrm{~nm}$.

\subsection{Sem and Tem Images}

The morphology of $\mathrm{NiO}$ nanoparticles was studied by scanning electron microscope (SEM) and by transmission electron microscope (TEM). The TEM samples were prepared by first dispersing the dried powder constituted of $\mathrm{NiO}$ particles in alcohol using ultrasonic excitation, then transferring the nanoparticles into the copper grid with carbon support film.

The particles are spherical shape with a narrow size distribution ranged from about $15 \mathrm{~nm}$ to $35 \mathrm{~nm}$ and an average size around $23 \mathrm{~nm}$, which is also supported by XRD spectrum data. The SEM image in figure 3 (b) reveals that the synthesized $\mathrm{NiO}$ is consisted of spherical shaped particles. The average particle size distribution can be estimated to lie within $20-40 \mathrm{~nm}$ range with average size is nearly equal to $25 \mathrm{~nm}$. 

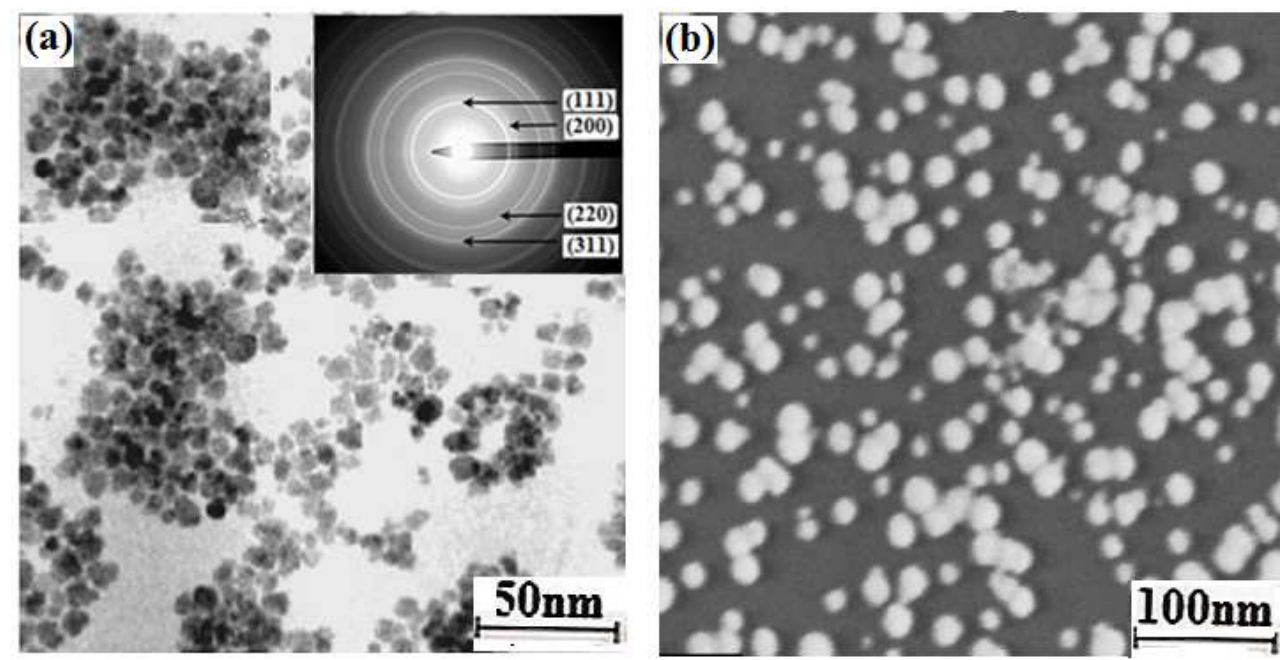

Figure 3. (a) A low magnification bright field TEM images of NiO nanostructures (insert, a selected area electron diffraction) and (b) SEM micrograph of NiO nanopowders.

\subsection{Energy Dispersive Studies (Eds)}

EDS analysis of nickel oxide nanoparticles was carried out by using internal standard at energy from $0 \mathrm{keV}$ to $10 \mathrm{keV}$. EDS spectrum (Figure 4) showed that the fabricated nanomaterial has mainly nickel and oxygen elements and there is small amount of about $1.2 \%$ of carbon detected in the spectrum (due to the polyvinyl alcohol used as caping agent in the preparing $\mathrm{NiO}$ nanoparticles). This confirms that the preprared nickel oxide was pure.

The experimental atomic percentages (figure 4, the insert) of $\mathrm{Ni}$ and $\mathrm{O}$ are found to be $46.6 \%$ and $52.2 \%$, respectively and the atomic ratio between $\mathrm{Ni}$ and $\mathrm{O}$ is about $1: 1.12$, which illustrates that the composition of the nickel oxide is non-stoichiometric.

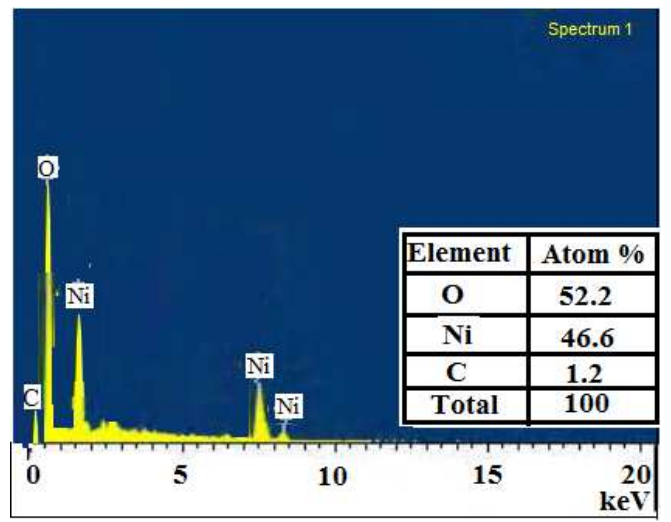

Figure 4. The EDAX spectra of NiO nanoparticles prepared under gamma irradiation.

\subsection{Ftir Study}

FT- IR spectroscopy (investigated region: 4000-400 $\mathrm{cm}^{-1}$ ) was carried at room temperature out in order to ascertain the purity and the nature of metal oxide nanopowder. The FT-IR spectrum of as-synthesized $\mathrm{NiO}$ nanoparticles is indicated in figure 5 .

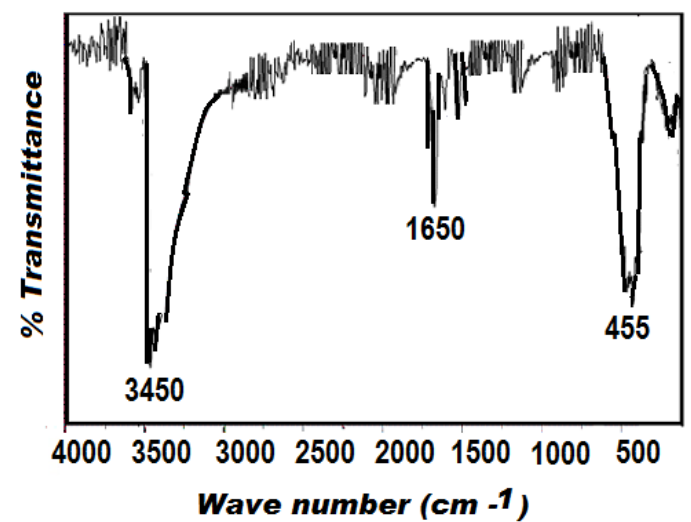

Figure 5. The FTIR spectrum of NiO nanoparticles prepared under gamma irradiation.

The spectrum showed significant absorption peaks at 3450 , 1650 and $455 \mathrm{~cm}^{-1}$. The band at $455 \mathrm{~cm}^{-1}$ was assigned to $\mathrm{Ni}-$ $\mathrm{O}$ stretching vibration mode [33]. The band which appeared at $3450 \mathrm{~cm}^{-1}$ is attributed to $\mathrm{OH}$ stretching of the polyvinyl alcohol used as caping agent in the preparing $\mathrm{NiO}$ nanoparticles and the band located at $1650 \mathrm{~cm}^{-1}$ has been assigned binding vibrations of absorbed water molecules on $\mathrm{NiO}$ nanoparticles

\subsection{Chemical Valence States by X-Ray Photoelectron Spectroscopy}

To further confirm the chemical nature of the $\mathrm{NiO}$ nanopowders, X-ray Photoelectron Spectroscopy (Figure 6) was carried out. The initial calibration of the instrument was conducted with a binding energy (B. E.) of $284.5 \mathrm{eV}$ for a C $1 \mathrm{~s}$ electron. As shown in Figure 6 , the pattern of the Ni $2 p$ core levels peaked at 854.8 and $873.2 \mathrm{eV}$ corresponding to the $\mathrm{Ni} 2 \mathrm{p}_{3 / 2}$ and $\mathrm{Ni} 2 \mathrm{p1} / 2$ states of the Ni-O bond, respectively. The binding energy located at 854.8 for the main $\mathrm{Ni} 2 \mathrm{p}_{3 / 2}$ and its satellite peak located at about $860 \mathrm{eV}$ confirms further the existence of $\mathrm{Ni}^{2+}$ ions. 
Moreover, the atomic ratio of $\mathrm{Ni}$ to $\mathrm{O}$ for the $\mathrm{NiO}$ sample was calculated to be nearly 1: 1 , which indicated that the oxidation state of $\mathrm{Ni}$ was +2 in the as-fabricated nonstochiometric $\mathrm{NiO}$ compounds [34]. The existence of $\mathrm{Ni}^{2+}$ would cause the $\mathrm{NiO}$ material to exhibit p-type conductivity even for stoichiometric composition [35].

The $\mathrm{O} 1 \mathrm{~s}$ peak at a binding energy of $529.6 \mathrm{eV}$ can be ascribed to $\mathrm{O}^{2-}$ anions in the $\mathrm{NiO}$ nanoparticles and is in agreement with reported data [34-36].
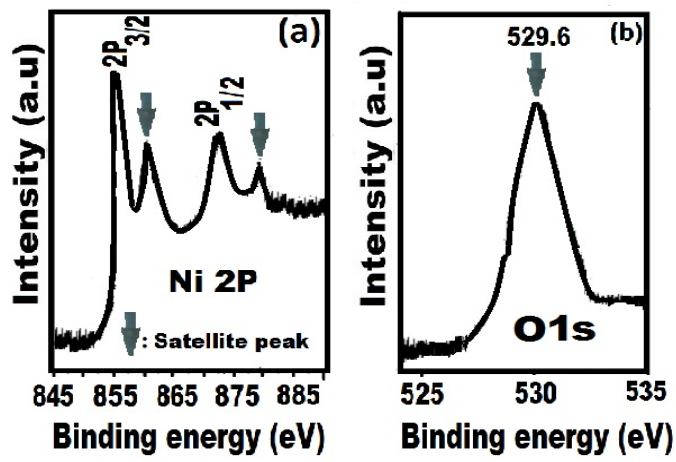

Figure 6. XPS spectra of (a) $\mathrm{Ni} 2 p$ and (b) Ols core levels of $\mathrm{NiO}$ nanopowders synthesized under gamma irradiation.

\subsection{Optical Studies}

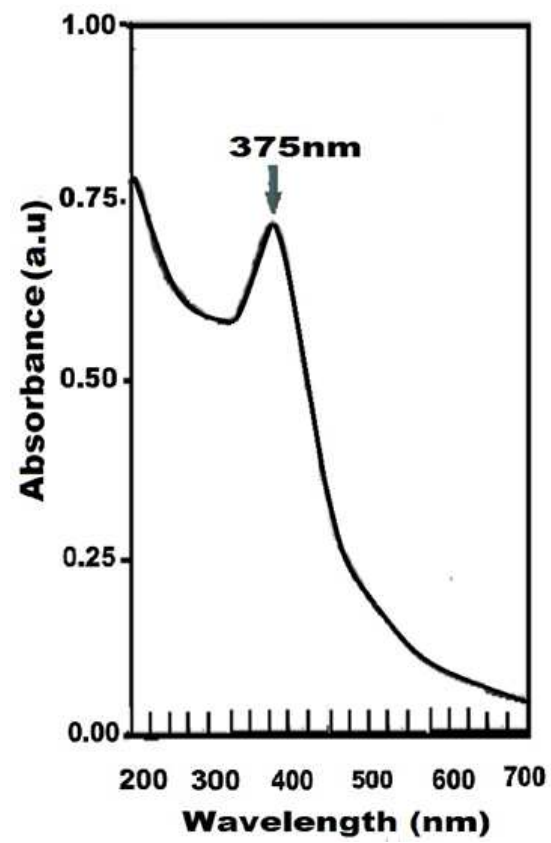

Figure 7. UV-visible spectrum of $\mathrm{NiO}$ nanoparticles dissolved in water at room temperature.3.7. Degradation of a Textile Azo Dye (Acid Red G) Using Nio/Uv Lamp.

The optical measurements of the as-prepared $\mathrm{NiO}$ sample was recorded at room temperature using UV-Visible absorption spectrophotometer in the range of 200 to $700 \mathrm{~nm}$. Figure 7 shows the optical absorption spectrum of $\mathrm{NiO}$ nanoparticles as a function of wavelength. The spectrum shows that the main characteristic peak at a wavelength of $375 \mathrm{~nm}$ corresponds to the formation of nickel. The of $\mathrm{NiO}$ exhibits a weak photoabsorption from in the visible light region, which implies the possibility of high photocatalytic efficiency of this material under visible light.

The prepared $\mathrm{NiO}$ was employed to study the photodegradation of a textile azo dye, acid red $\mathrm{G}$, which was chosen as a pollutant model (structure insert in Figure 10). The structure of the dye is characterized by sulphonic groups, which are responsible for the high solubility of this dye in water. When dissolved in distilled water, the UV-visible spectrum of acid red $G$ showed one main band at $\lambda=530 \mathrm{~nm}$ (with higher molar absorption coefficient) corresponding to the $\mathrm{n} \rightarrow \pi^{*}$ transition of the azo bond.

The UV-visible spectrum of acid red G recorded at $\mathrm{pH} 2.5$ is shown in Figure 10 as initial solution. The band at $\lambda=530 \mathrm{~nm}$ was used to monitor the degradation of acid red $\mathrm{G}$.

The photoreactor setup for this experiment is presented in Figure 9. The reactor cell was a $1000 \mathrm{~mL}$ cylindrical pyrexglass with an inside reflective surface. It was an open system and was not insulated. The rector was placed inside an enclosed compartment $(12 \mathrm{~cm} \times 8.0 \times 28 \mathrm{~cm})$ made of polyvinyl chloride (PVC) plates. Twelve high-pressure mercury UV lamps $(12 \times 6$ watt emitting at $365 \mathrm{~nm}$, provided by Beijing Institute of Electric Light Source, China) were mounted inside the PVC compartment. They were arranged vertically and cylindrically around the reactor. The distance between each lamp inside the compartment was about $3 \mathrm{~cm}$ and each lamp was $18 \mathrm{~cm}$ long. The lamps were placed $4 \mathrm{~cm}$ away around the reactor and the UV light intensity could be controlled by the use of four switches attached on the PVC compartment. Each switch, once turned on could allow the function of $3 \mathrm{UV}$ lamps. There was no concentration of light inside the photo reactor (the system is outdoors and not insulated). The holes around the PVC compartment cool the reactor system, and then prevent the reaction solution overheating. The transmittance of light in Pyrex glass was estimated to be $77 \%$ at $365 \mathrm{~nm}$ UV irradiation.

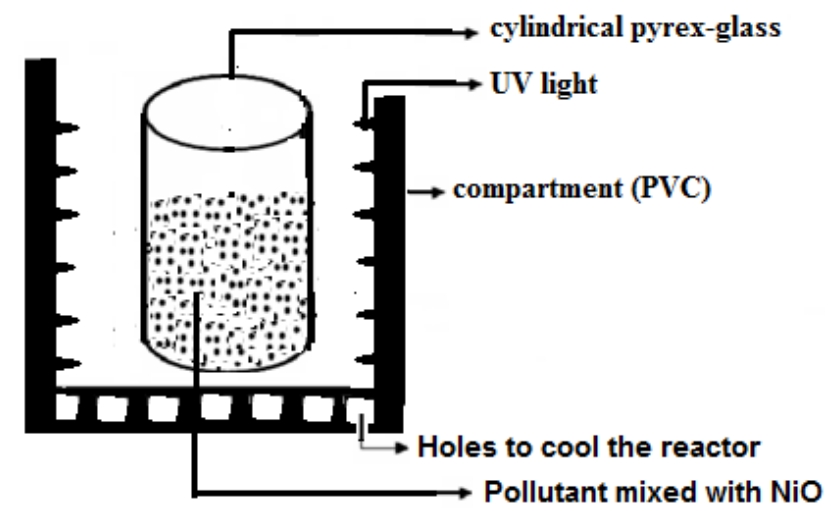

Figure 8. The schematic diagram of the experimental reactor setup used for the dye degradation.

The photocatalytic degradation of acid red $\mathrm{G}$ was studied by taking $100 \mathrm{ml}$ distilled water containing $15 \mathrm{ppm}$ of the dye and $50 \mathrm{mg}$ of $\mathrm{NiO}$. The reaction mixture was irradiated under UV light.

The remaining concentration of the dye during the photodegradation was measured by plotting a calibration 
curve from Beer-Lambert law. It was assumed that the BeerLambert law works over the whole concentration range.

The maximum experimental temperature was kept about $30 \pm 3^{\circ} \mathrm{C}$. Throughout the degradation experiments, sample aliquots were regularly collected from the reactor every 30 minutes in a test tube to monitor the breakup of acid red $\mathrm{G}$ aqueous solution with spectrophotometer methods (refer to Figure 10).

The photodegradation of acid red $G$ was quantified as time-dependent normalized dye concentration, which is the dye concentration removed at any time $\left(\mathrm{C}_{0}-\mathrm{Ct}\right)$ divided by initial dye concentration $\left(\mathrm{C}_{0}\right), \mathrm{C}_{\mathrm{t}}$ is the remaining concentration of the dye at any time. The photodegradation of acid red $\mathrm{G}$ after 5 hours of $\mathrm{UV}$ illumination was about $95 \%$ at $\mathrm{pH} 2.1$

The experimental results as evidenced in Figure 9 showed that the $\mathrm{NiO}$ enhanced the photodegradation of acid red $\mathrm{G}$. In the system $\mathrm{UV} / \mathrm{NiO}$ almost $95 \%$ of acid red G 15 ppm was decolorized in $5 \mathrm{~h}$ and without UV lamp (in dark) in the presence of $\mathrm{NiO}$ semi-conductor no degradation was observed.

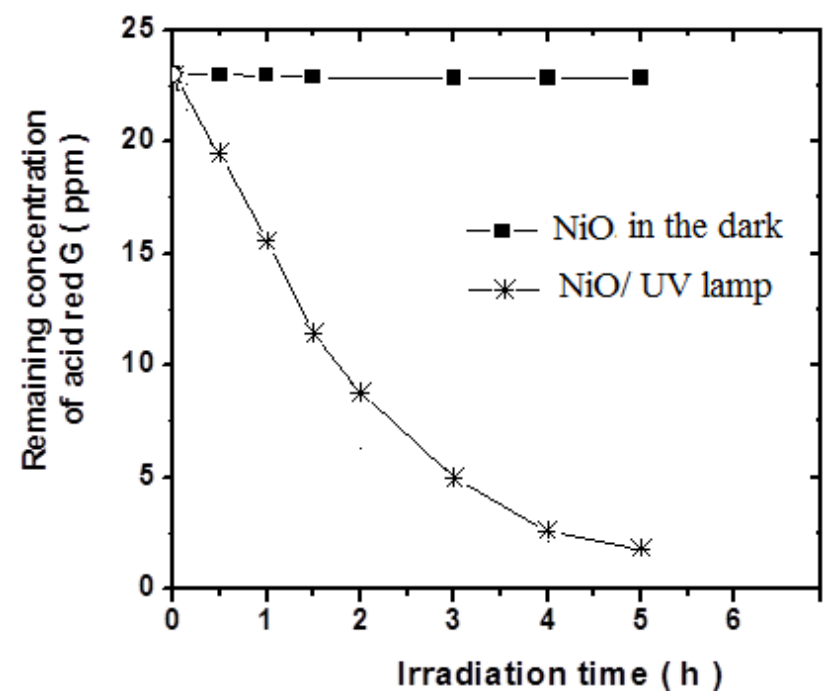

Figure 9. Degradation of acid red $\mathrm{G}$ in the presence of 50mg of $\mathrm{NiO}$ nanoparticles.
During the photocatalytic oxidation, the UV bands intensity at 530nm corresponding to the azo bound decreased significantly with irradiation time. When the irradiation time was increased to $5 \mathrm{~h}$, the degradation of acid red $\mathrm{G}$ was nearly about $95 \%$. This feature implies that the azo bond $(-\mathrm{N}=\mathrm{N}-)$ in the structure of acid red $\mathrm{G}$ was cleaved. This result shows that the $\mathrm{NiO}$ exhibit good photocatalytic activity. The surface interface of the combined systems $\mathrm{NiO}$ significantly influenced on the structure relation properties.

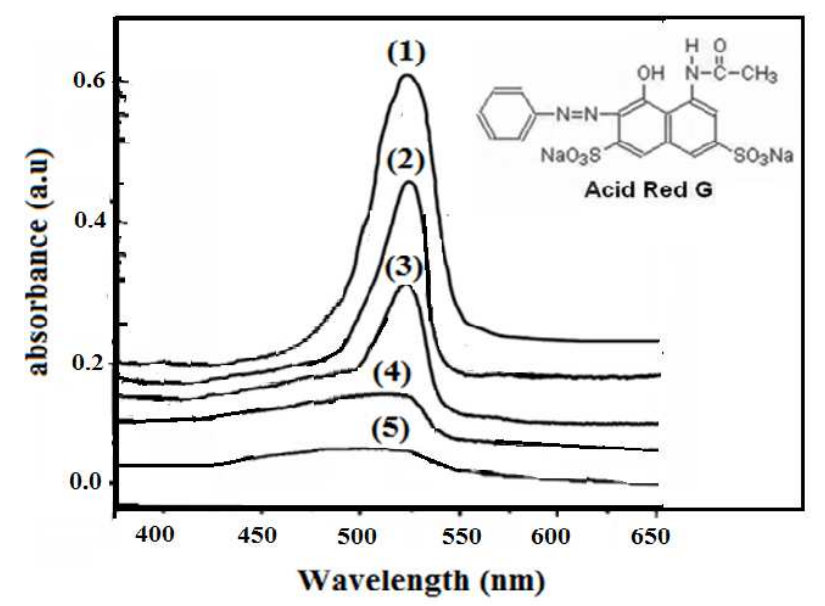

Figure 10. Evolution in time of absorption spectra of acid red $G$ (15 ppm, pH 2.1) aqueous solution with $\mathrm{NiO}$ nanoparticles (NiO: 50mg), (1): initial solution, (2): $1 \mathrm{~h},(3): 2 \mathrm{~h},(4): 3 \mathrm{~h}$ and (5): 5 h irradiation.

\subsection{Proposed Reaction Mechanism of Nio Nanoparticles Formation}

From the experiment, the following mechanism could be suggested to illustrate the formation of $\mathrm{NiO}$ under gamma irradiation process.

It is well known that, the radiolysis of water produces free radicals such as: - $_{\text {aq }}, \mathrm{H} \cdot, \mathrm{OH} \cdot$ and $\mathrm{HO}_{2}$ or $\mathrm{O}_{2}$ - and molecular products such as $\mathrm{H}_{2}$ and $\mathrm{H}_{2} \mathrm{O}_{2}$. It was reported that, hydrated electron, e- ${ }_{\text {aq }}$ and hydrogen radical $\mathrm{H} \cdot$ are reducing species, the standard electrode potentials of $\mathrm{e}_{-\mathrm{aq}}$ and $\mathrm{H} \cdot$ radical at $25^{\circ} \mathrm{C}$ being $-2.77 \mathrm{~V}$ and $-2.31 \mathrm{~V}$ respectively and $\mathrm{OH} \cdot \mathrm{HO}_{2}$, $\mathrm{O}_{2^{-}}, \mathrm{H}_{2} \mathrm{O}_{2}$ are oxidizing species $[37,38]$.

$$
\mathrm{H}_{2} \mathrm{O} \stackrel{\gamma \text {-rays }}{\longrightarrow} \mathrm{H}_{2}, \mathrm{H}_{2} \mathrm{O}_{2}, \mathrm{H}^{\bullet}, \mathrm{HO}^{\bullet}, e_{a q}^{-}, \mathrm{H}_{2} \mathrm{O}^{+}, \mathrm{H}_{2} \mathrm{O}^{*}, \mathrm{HO}_{2}
$$

The formation of the final $\mathrm{NiO}$ nanoparticles occurs via the oxidation of the $\mathrm{Ni}(\mathrm{OH})_{2}$ to oxyhydroxy nickel, $\mathrm{NiOOH}$ and finally, the reduction of $\mathrm{NiOOH}$ to $\mathrm{NiO}$ can be effectively coupled with the oxidation of $\mathrm{H}_{2} \mathrm{O}_{2}$ to $\mathrm{O}_{2}$, which explains the conversion of $\mathrm{NiOOH}$ to $\mathrm{NiO}$ under $\gamma$-irradiation.

$$
\mathrm{Ni} 2++2 \mathrm{OH}-\rightarrow \mathrm{Ni}(\mathrm{OH}) 2 \text { (green-coloured) }
$$

The $\mathrm{Ni}(\mathrm{OH})_{2}$ then undergoes oxidation to form $\mathrm{NiOOH}$ via through reaction:

$$
\mathrm{Ni}_{2}+(\mathrm{sol})+\bullet \mathrm{OH} \rightarrow\left[\mathrm{Ni}(\mathrm{OH})_{3}\right] \rightarrow \mathrm{Ni} \mathrm{OOH}+\mathrm{H}_{2} \mathrm{O}
$$

It was observed that, isopropyl alcohol did not totally act as scavenger for oxidative $\mathrm{OH} \cdot$ radicals, produced during the radiolysis of water under gamma irradiation

$$
(\mathrm{CH} 3) 2 \mathrm{CHOH}+\bullet \mathrm{OH} \rightarrow(\mathrm{CH} 3) 2 \mathrm{C} \bullet \mathrm{OH}+\mathrm{H} 2 \mathrm{O}
$$

Some amount of the remained ${ }^{\circ} \mathrm{OH}$ in the solution could act directly as oxidizing agent (Equation 4) or could recombined to produce $\mathrm{H}_{2} \mathrm{O}_{2}$.

$$
\bullet \mathrm{OH}+\bullet \mathrm{OH} \rightarrow \mathrm{H}_{2} \mathrm{O}_{2}
$$

The reduction of $\mathrm{NiOOH}$ to $\mathrm{NiO}$ is accelerated in the presence of $\mathrm{H}_{2} \mathrm{O}_{2}$ via the reaction:

$$
2 \mathrm{NiOOH}+3 \mathrm{H}_{2} \mathrm{O}_{2} \rightarrow 2 \mathrm{NiO}+2 \mathrm{O}_{2}+4 \mathrm{H}_{2} \mathrm{O}
$$




\section{Conclusion}

Spherically shaped $\mathrm{NiO}$ nanoparticles (with an average size of $23 \mathrm{~nm}$ ) were prepared successfully by $\gamma$-irradiation technique at room temperature, ambient pressure, without catalysts, in water system. The optical properties of the asprepared NiO show that the samples exhibited photo absorption in UV light region, which implies the possibility of high photocatalytic efficiency of these materials under UV light. The results conclude that the fabricated nickel oxide nanoparticles have higher activity for the degradation of acid red G.

\section{Acknowledgements}

The authors gratefully thank Dr. Xin Lihui of the National Center of Shanghai Institute of Measurement and Testing Technology for his help with SEM, TEM, Magnetization, FT- IR spectroscopy analysis and XRD analysis, as well as Professor Dr Zhou Ruimin of Shanghai Applied Radiation Institute, Shanghai University, for his support for this work.

\section{References}

[1] Taghizadeh F, The study of Structural and Magnetic properties of $\mathrm{NiO}$ nanoparticles, Optics and Photonics Journal $6(8), 2016,164-169$.

[2] Miao S, Shuai W, Chun-Jiang J et al, Effet of nickel oxide doping to ceria supported gold catalyst for $\mathrm{CO}$ oxidation and water-gas shift reactions, Catalysts, 8 (12), 2018, 584-586.

[3] Mohammed Ali N, Futeme K, Batol Z, Catalytic activity of reusable nickel oxide nanoparticles in the synthesis of spiro oxindoles, RSC Advances, 5, 2015, 26517-26520.

[4] Mohamed, B. Z., Ming, H., Rahul, R. S., et al. Controlled synthesis of nanoporous nickel oxide with two-dimensional shapes through thermal decomposition of metal-cyanide hybrid coordination polymers, Chem Eur J, 21, 2015, 3605-3612.

[5] Mohammed A, Abdul A, Muhammad Q et al., Influence of pamoic acid as a complexing agent in the thermal preparation of $\mathrm{NiO}$ particles: Application to electrochemical water oxidation, Chemistry Select, 3 (2), 2018, 573-580.

[6] Kumar Rai A, Tuan Anh L, Park C-J, Kim J. et al. Electrochemical study of $\mathrm{NiO}$ nanoparticles electrode for application in rechargeable lithium-ion batteries Ceram Int, 39, 2013, 6611-6618.

[7] Aguilera-del-Toro R H, Aguilera-Granja F, Balbas L C et al., Structure, fragmentation patterns and magnetic properties of small nickel oxide clasters, Phys. Chem. Phys., 19, 2017, 3366-3383.

[8] Marin T, Dobrica N, Matgaz P et al., Magnetic properties of $\mathrm{NiO}$ (nickel oxide) nanoparticles: Blocking temperature and Neel temperature, Journal of Alloys and Compounds, 647, 2015, 1061-1068.

[9] David Muneton A, Jessica M, J antillan et al. Synthesis of Ni nanoparticles by Femtosecond laser ablation in liquids: structure and sizing, J. Phys. Chem. C, 119 (23), 2015, 1318413193.

[10] Schmidt, G. Nanoparticles: From Theory to Application; VCH: Weinheim, Germany, 2004.

[11] Chuen L, Changling L, Kazi A et al., Template free and binderless $\mathrm{NiO}$ nanowire foam for Li-ion battery anodes with long life and ultrahigh rate capability, Scientific Reports 6, 2016, 29183-29186.

[12] Mohamed R A, Taymour H, Sabah E. et al., Optical and electrical behaviors in $\mathrm{NiO} / \mathrm{x} \mathrm{Fe}_{2} \mathrm{O}_{3}$ nanoparticles synthesized by microwave irradiation method, Optical Materials, 75, 2018, 869-874.

[13] Ceylan, A., Rumaiz, A. K. and Shah, S. I. et al. Inert gas condensation of evaporated $\mathrm{Ni}$ and laser ablated CoO. J Appl Phys, 101, 2007, 094302.

[14] Amgad S. Danial, M. M. Saleh, S. A. Salih, et al., On the synthesis of nickel oxide nanoparticles by sol-gel technique and its electrocatalytic oxidation of glucose, Journal of Power Sources, 293, 2016, 101-108.

[15] Nurul N M Z, Noor H M K, Ahmad A M, Synthesis of NiO Nanoparticles through Sol-gel Method, Procedia Chemistry, 19, 2016, 626-631.

[16] Nabasava V. G, Ravishankar B, Raghunandan D et al., Synthesis and characterization of nickel oxide nanoparticles by self-propagating low temperature combustion method, Recent Research in Science and Technology, 4 (4), 2012, 50-53.

[17] Sathisha D, Gopala Krishina N, Synthesis and characterization of nickel oxide nanostructures by hydrothermal method, Journal of Computational and theoretical Nanoscience, 24 (8), 2018, 5691-5694.

[18] Nilolic D, Panjan M, Blake G R et al., Annealing dependent structural and magnetic properties of nickel oxide $(\mathrm{NiO})$ nanoparticles in silica matrix, Journal of the European Ceramic Society, 35 (14), 2015, 3843-3852.

[19] Assem B, Mousa Al-Noaimi, Mohammed S, et al., One Step Synthesis of $\mathrm{NiO}$ Nanoparticles via Solid-State Thermal Decomposition at Low-Temperature of Novel Aqua (2, 9dimethyl-1, 10-phenanthroline) $\mathrm{NiCl}_{2}$ Complex, Int. J. Mol. Sci., 14, 2013, 23941-23954.

[20] Pooja K, Dipali S, Synthesis and characterization of nickel oxide nanoparticles by using co-precipitation method, International Journal of Advanced Research 5 (5), 2017, 1333-1338.

[21] Javad M, Elham H, Fabrication and characterization of $\mathrm{NiO}$ nanoparticles by precipitation from aqueous solution, Korean Journal of Chemical Engineering, 31 (3), 2014, 503-508.

[22] Lay G T, Kun-Dar L, Yi H L, Synthesis and characterization of $\mathrm{Ni} / \mathrm{NiO}$ core-shell nanoparticles prepared by surfactantmediated method, Nanoscience and Nano technology Letters, 3 (6), 2011, 798-804.

[23] Mohamed J, I Sta, Messaoud $\mathrm{H}$ et al., Synthesis and characterization of metal oxide thin films deposited on glass substrates using spray pyrolysis, Applied Surface, 308, 2014, 199-205.

[24] Soheil A, Milad T, Amir A, Simple new sythesis of nickel oxide $(\mathrm{NiO})$ in water using microwave irradiation, Journal of Materials in Electronics, 3, 2017, 28-31. 
[25] Elvin R B, Kremar S, Samatha E B et al., Solvothermal synthesis of crystalline nickel oxide nanoparticles, Materials Chemistry and Physics, 115 (1), 2009, 371-377.

[26] Alam A, Abdul Razak D, Muhammad Azmi A H et al., A Review on radiation-induced nucleation and growth of colloidal metallic nanoparticles, Nanoscale Research Letters 8, 2013, 474.

[27] Wren JC, Steady-State Radiolysis: Effects of Dissolved Additives. ACS Symposium, Nuclear Energy and the Environment Series, American Chemical Society, Washington, DC, Chap 22, 2010, 271-295.

[28] Joseph JM, Choi B-S, Yakabuskie PA et al, A combined Experimental and model analysis on the effect of $\mathrm{pH}$ and $\mathrm{O}_{2}$ (aq) on $\gamma$-radiolytically produced $\mathrm{H}_{2}$ and $\mathrm{H}_{2} \mathrm{O}_{2}$, Radiat. Phys. Chem. 77, 2008, 1009-1020.

[29] Ekoko Bakambo G., Joseph K. -K. Lobo, Omer M. Mvele, et al, Gamma Irradiation Inducing the Synthesis of Magnetic $\mathrm{Fe}_{3} \mathrm{O}_{4}$ Nanorod Particles in Alkaline Medium, International Journal of Materials Science and Applications, 3 (6), 2014, 339-343.

[30] Ekoko Bakambo G, Zhou Ruimin, Xin LiHui et al, Effect of $\mathrm{pH}$ on the morphology of iron oxides synthesized under gamma irradiation, Journal of Radiaoanalytical and Nuclear Chemistry 270 (2), 2006, 473-478.

[31] Jérémie L. Muswema, Gracien B. Ekoko, Joseph K. -K. Lobo et al., Gamma-radiation induced synthesis of spinel $\mathrm{Co}_{3} \mathrm{O}_{4}$ nanoparticles, SN Applied Sciences 1: 333, 2019, https://doi.org/10.1007/s42452-019-0342-6.
[32] Deepa M. Audi, A review of synthesis of Nickel Oxide by different routes and its Photocatalytic and Microbial study, Res. J. Recent Sci. 6 (11), 2017, 16-22.

[33] K. M. Mayya, N. Jain, A. Gole et al, Time-depedent complexation of glucose-reduced gold nanoparticles with octadecylamine Langmuir monolayers, Journal of Colloid and Interface Science, 270, 2004, 133-139.

[34] Shu HM, Xie JM, Xu H, et al. Structural characterization and photocatalytic activity of $\mathrm{NiO} / \mathrm{AgNbO}_{3}$, Journal of Alloys and Compounds, 496 (1-2), 2010, 633-637.

[35] Wang $\mathrm{H}$, Zhao $\mathrm{Y}, \mathrm{Wu} \mathrm{C}$, et al, Ultraviolet electroluminescence from $\mathrm{n}-\mathrm{ZnO} / \mathrm{NiO} / \mathrm{p}-\mathrm{GaN}$ lightemitting diode fabricated by MOCVD, Journal of Luminescence, 158, 2015, 6-10.

[36] Chen SC, Kuo TY, Sun TH, Microstructures, electrical and optical properties of non-stoichiometric p-type nickel oxide films by radio frequency reactive sputtering, Surface and Coatings Technology, 205 (Suppl 1), 2010, S236-S240.

[37] Buxton GV, Greenstock CL, Helman WP, Critical Revieuw of rate constants for reactions of hydrated electrons, hydrogen atoms and hydroxyl radicals $\left({ }^{\circ} \mathrm{OH} /{ }^{\circ} \mathrm{O}^{-}\right)$in aqueous solution, $\mathrm{J}$ Phys Chem Ref Data 17, 1988, 513-886.

[38] Spinks JWT, Woods RJ An Introduction to Radiation Chemistry. 3nd edition, Wiley-InterScience, New York, 1990, 285. 